\title{
Atrophy of medial temporal lobes on MRI in "probable" Alzheimer's disease and normal ageing: diagnostic value and neuropsychological correlates
}

Ph Scheltens, D Leys, F Barkhof, D Huglo, H C Weinstein, P Vermersch, M Kuiper, M Steinling, E Ch Wolters, J Valk

\begin{abstract}
Magnetic resonance imaging (MRI) has shown a great reduction in medial temporal lobe and hippocampal volume of patients with Alzheimer's disease as compared to controls. Quantitative volumetric measurements are not yet available for routine clinical use. We investigated whether visual assessment of medial temporal lobe atrophy (MTA) on plain MRI films could distinguish patients with Alzheimer's disease $(n=21)$ from age matched controls $(n=21)$. The degree of MTA was ascertained with a ranking procedure and validated by linear measurements of the medial temporal lobe including the hippocampal formation and surrounding spaces occupied by cerebrospinal fluid.

Patients with Alzheimer's disease showed a significantly higher degree of subjectively assessed MTA than controls $(p=0.0005)$. Linear measurements correlated highly with subjective assessment of MTA and also showed significant differences between groups. Ventricular indices did not differ significantly between groups. In Alzheimer's disease patients the degree of MTA correlated significantly with scores on the mini-mental state examination and memory tests, but poorly with mental speed tests. This study shows that MTA may be assessed quickly and easily with plain MRI films. MTA shown on MRI strongly supports the clinical diagnosis of Alzheimer's disease, is related to memory function, and seems to occur earlier in the disease process than does generalised brain atrophy.
\end{abstract}

(F Neurol Neurosurg Psychiatry 1992;55:967-972)

One of the first and most striking manifestations of Alzheimer's disease is memory impairment. The hippocampus and adjacent structures are crucial to memory; their bilateral destruction leads invariably to the loss of this essential intellectual faculty. ${ }^{1-3}$ Ball et al have stated that Alzheimer's disease is mainly a "hippocampal dementia" and have shown nerve cell loss and gliosis in both hippocampi of diseased patients while other brain regions were unaffected. ${ }^{4}$ Other pathological studies have also incriminated the temporal basal gray matter structures, including the hippocampus, as the brain areas affected earliest and most severely by Alzheimer's disease. ${ }^{5}$

Recent neuroimaging studies have also focused attention on these structures. A computed tomography (CT) study by de Leon and coworkers reported a significant widening of the hippocampal fissure in Alzheimer's disease patients. ${ }^{6} \mathrm{CT}$ imaging of the temporal lobes, however, is hampered by bone hardening artifact and a limited viewing angle; it shows enlargement of the temporal horns and widening of the hippocampal fissures as indirect changes due to atrophy of the hippocampal complex. Magnetic resonance imaging (MRI) yields superior visualisation of the medial temporal lobe, including the hippocampus. ${ }^{7-9}$ It also allows an imaging plane perpendicular to the long axis of the hippocampus, thus reducing volume averaging. MRI technique permits direct visualisaton of the hippocampal formation in substantial cytoarchitectonic detail. $^{8}$

Two studies have shown over $40 \%$ reduction in hippocampal volume in Alzheimer's disease patients as compared to controls. ${ }^{710}$ Quantitative volumetric measurements, however, are not yet available for routine clinical use and therefore we investigated whether a visual assessment of medial temporal lobe atrophy (MTA) on plain MRI films could distinguish Alzheimer's disease patients from controls. Validation of visually assessed atrophy was attempted by linear measurements of the medial temporal lobe. For comparison we obtained two indices of general ventricular enlargement to study their ability to separate groups. We also studied whether medial temporal lobe atrophy correlated with neuropsychological impairment in patients with "probable" Alzheimer's disease.

\section{Subjects and methods}

Patients

This study was carried out in Amsterdam, Netherlands, and in Lille, France. Forty two right handed subjects (21 Alzheimer's disease, 21 controls) were included: 21 were French speaking (11 Alzheimer's disease, 10 controls) and 21 were Dutch speaking (10 Alzheimer's disease, and 11 controls). The group with Alzheimer's disease included 19 women and two men, mean (SD) age 72.8 (11.5) years (range 52-90 years), with a mean mini-mental 
state examination ${ }^{11}$ score of $14.9(6 \cdot 17)$ (range 1-24). The diagnosis of "probable" Alzheimer's disease was made according to current research criteria. ${ }^{12}$ We excluded patients with evidence of neurological disease other than Alzheimer's disease, incuding toxic, metabolic, traumatic, demyelinating, neoplastic, or focal cerebrovascular disease. Each subject had a Hachinski score of 3 or less. ${ }^{13}$ None of the patients suffered from arterial hypertension, diabetes mellitus, or cardiac disease, according to our previously published criteria. ${ }^{14}$ Nine patients had presenile Alzheimer's disease (onset before 65th year) and 12 had senile Alzheimer's disease. None of them had a definite family history of the disease but two had a first degree relative suffering from dementia, without sufficient data available to make a diagnosis of Alzheimer's disease. None of the patients displayed myoclonus or extrapyramidal signs.

\section{Controls}

Control subjects were healthy volunteers. They were spouses of patients or volunteers from a general practice. These subjects ( 8 women, 13 men; mean age $70.9(10.6 ; 54-94)$ years) had no history of mental decline or strokes and had a mini-mental state examination score higher than 27 (mean 29.7 (0.56)). Each of them had given informed consent after the nature of the procedure had been fully explained.

Figure 1 Midsagittal T1 weighted scout image on which six oblique slices are planned parallel to the brainstem axis.

\section{Table 1 Visual rating of medial temporal lobe atrophy}

\begin{tabular}{llll}
\hline Score & $\begin{array}{l}\text { Width of } \\
\text { choroid fissure }\end{array}$ & $\begin{array}{l}\text { Width of } \\
\text { temporal horn }\end{array}$ & $\begin{array}{l}\text { Height of } \\
\text { hippocampal } \\
\text { formation }\end{array}$ \\
\hline 0 & $\mathrm{~N}$ & $\mathrm{~N}$ & $\mathrm{~N}$ \\
1 & $\uparrow$ & $\mathrm{N}$ & $\mathrm{N}$ \\
2 & $\uparrow \uparrow$ & $\uparrow$ & $\downarrow$ \\
3 & $\uparrow \uparrow \uparrow$ & $\uparrow \uparrow$ & $\downarrow \downarrow$ \\
4 & $\uparrow \uparrow \uparrow$ & $\uparrow \uparrow \uparrow$ & $\downarrow \downarrow \downarrow$
\end{tabular}

$\uparrow=$ increase, $\downarrow=$ decrease. $N=$ normal.

\section{MRI technique}

MRI was performed on an MR-max (General Electric) with a superconducting magnet operating at a field strength of 0.5 tesla, or on a Teslacon II (Technicare) operating at 0.6 tesla. T1 weighted spin echo sequences were used (TR $300 \mathrm{~ms}$, TE $22 \mathrm{~ms}$, six sequences, field of view 20). Six oblique slices (slice thickness $5 \mathrm{~mm}$, interslice gap $1 \mathrm{~mm}$, in plane resolution $0.8 \times 1.0 \mathrm{~mm}$ ) parallel to the brainstem axis were planned from a midsagittal scout image (fig 1). In both centres the first image was planned directly adjacent to the brainstem, resulting in identical images for all subjects. Total acquistion time was six minutes.

\section{MRI analysis}

MTA was assessed visually by five of us who were blinded to diagnosis and age of the subjects. A definite score was assigned when consensus was reached. The procedure was performed as follows. All 42 scans were ranked from absent to severe atrophy, judged on all six slices. The scans were then pooled in groups with various degrees of atrophy, resulting in five different scores $(0-4)$, subsequently referred to as subjective MTA score. The characteristics of each group were later defined in terms of height of the hippocampal formation (hippocampus and parahippocampal gyrus) and enlargement of the surrounding cerebrospinal fluid spaces, for application by others (table 1). Example are shown in figure 2. In addition, four linear measures of the medial temporal lobe (A, B, C, D) were calculated on both sides (left and right). A was the greatest height of the hippocampal formation, defined as the dentate gyrus, hippocampus proper, and subiculum together with the parahippocampal gyrus; $B$ was the greatest

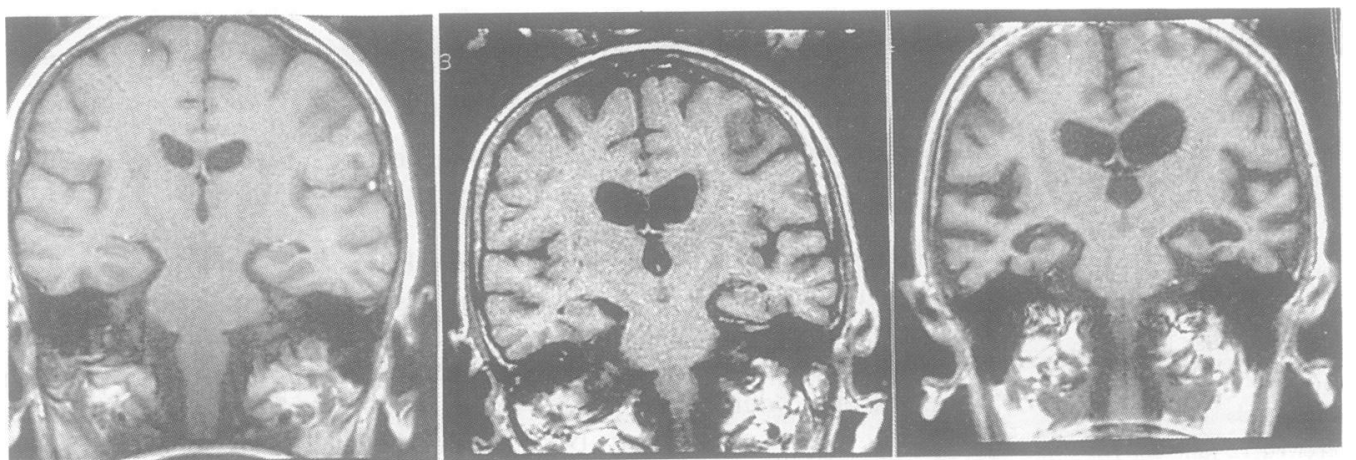

Figure 2 Oblique T1 weighted images through the medial temporal lobe, showing increasing atrophy as examples of the subjective scores 0 (control) and 2 and 4 (patients). Increasing loss of height of hippocampal formation and parahippocampal gyrus is evident, together with progressive widening of choroid fissures and temporal horns. 
width between the hippocampal formation and the brainstem; $C$ was the vertical width of the choroid fissure centred on the midpoint of the hippocampus; and $\mathrm{D}$ was the width of the temporal horn (fig 3). These measures were divided by the width between the inner tables of the calvarium on the same level, designated as the brain width, resulting in four linear indices (AI, BI, CI, and DI) for each side.

For comparison we measured the lateral ventricular index and the third ventricle index on the same slice used for the temporal indices. The ventricular index (VI) was defined as the width between the lateral ventricles divided by the width between the inner tables of the calvarium on the same level and the third ventricle index (V3I) was defined as the width of the third ventricle divided by the width between the inner tables of the calvarium on the same level. This method is essentially the same as described for CT. ${ }^{15}$

All linear measurements were taken on the slice that best depicted both hippocampal formations, usually the fourth slice, after magnification of the hard copy of the scan by projecting it on a screen with an overhead projector to five times real size. The measurements were later divided by five, providing actual sizes. Linear measurements were performed by two neuroradiologists together in one session.

\section{Neuropsychological assessment}

Neuropsychological tests were performed in Alzheimer's disease patients by an investigator whose native language was the same as that of the patient. Tests were standardised in both languages. They consisted of tests for memory and mental speed.

Memory was evaluated by the Fuld object memory evaluation, ${ }^{16}$ Wechsler logical memory test ${ }^{1.7}$ for free recall, the digit $\operatorname{span}^{18}$ for immediate verbal memory, and word fluency ${ }^{18}$ for semantic memory (categorical names of foods). The object memory evaluation consisted of a "tactile" part in which 10 common objects in a bag were presented to patients to determine whether they could identify objects by touch (stereognosis), providing a "tactile"

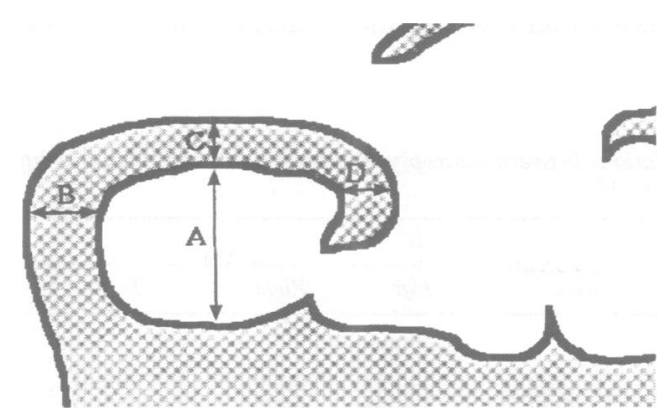

Figure 3 Schematic drawing showing linear measures of medial temporal lobe. $A=$ largest vertical height of hippocampal formation, defined as dentate gyrus, hippocampus proper, and subiculum together with parahippocampal gyrus; $B=$ largest horizontal width between hippocampal formation and brainstem; $C=$ largest vertical width of choroid fissure; $D=$ width of temporal horn. score. After naming or describing the object the patient took the object out to "see if (s)he was right" and to name the object if it had not been recognised by touch, providing a "visual" score. The scores for tactile and visual recognition were summed. Next the patient was asked to recall the objects from the bag, and was given four more chances to learn and recall them. Recall was tested 15 minutes later and a recall score obtained.

Mental speed was assessed by the trail making test, part $A,{ }^{18}$ and the digit symbol substitution test. ${ }^{19}$ The trail making and word fluency tests were performed during the 15 minute period between the fifth trial and the delayed recall of the object memory evaluation. The minimental state examination was used as a measure of the severity of dementia in Alzheimer's disease patients.

\section{Statistical analysis}

Groups were compared using means and 95\% confidence intervals obtained by a $t$ test. Ordinal variables were compared with the Mann Whitney U test. Correlations were calculated with Spearman's non-parametric rank correlation test $\left(\mathbf{r}^{\prime}\right)$, with Bonferroni's correction for multiple comparisons when appropriate. $p$ Values $<0.05$ were regarded as significant. Null hypotheses were tested two sided. Data were analysed with the SPSS/PC statistical package.

\section{Results}

The groups did not differ significantly with respect to mean age and mean brain width. In the control group the brain width and the subjective score were not significantly different between men and women.

The breakdown of the subjective MTA scores is given in figure 4 . Seventeen out of 21 (81\%) patients had scores ranging from 2 to 4 , while $14 / 21(67 \%)$ controls had scores of 0 or 1. None of the controls had a score of 4 , and one patient had a score of 0 (further details of this patient are given in the discussion). The difference between groups was significant $(p=0.0005)$. The subjective score did not

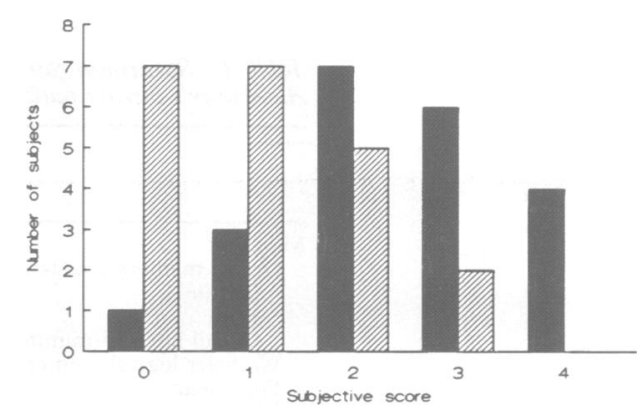

Figure 4 Breakdown of subjective scores of medial temporal lobe atrophy in Alzheimer's disease patients (solid bars) and controls (hatched bars). Difference is significant ( $p=0.0005$, Mann Whitney $U$ test). 
Table 2 Mean (95\% CI) of linear indices for patients with Alzheimer's disease and controls

\begin{tabular}{|c|c|c|c|}
\hline & $\begin{array}{l}\text { Alzheimer's disease } \\
\text { patients }\end{array}$ & Controls & p Value \\
\hline \multicolumn{4}{|l|}{ A: } \\
\hline $\begin{array}{l}\text { left } \\
\text { left }\end{array}$ & $\begin{array}{l}0.155(0.138 \text { to } 0.172) \\
0.166(0.153 \text { to } 0.179)\end{array}$ & $\begin{array}{l}0.182(0.169 \text { to } 0.194) \\
0.192(0.181 \text { to } 0.203)\end{array}$ & $\begin{array}{l}0.02 \\
0.007\end{array}$ \\
\hline \multicolumn{4}{|c|}{ (2) } \\
\hline $\begin{array}{l}\text { left } \\
\text { right }\end{array}$ & $\begin{array}{l}0.059(0.046 \text { to } 0.072) \\
0.062(0.051 \text { to } 0.073)\end{array}$ & $\begin{array}{l}0.056(0.046 \text { to } 0.066) \\
0.059(0.050 \text { to } 0.068)\end{array}$ & $\begin{array}{l}\text { NS } \\
\text { NS }\end{array}$ \\
\hline \multicolumn{4}{|c|}{ (10 } \\
\hline $\begin{array}{l}\text { left } \\
\text { right }\end{array}$ & $\begin{array}{l}0.035(0.025 \text { to } 0.045) \\
0.034(0.022 \text { to } 0.046)\end{array}$ & $\begin{array}{l}0.019(0.014 \text { to } 0.024) \\
0.014(0.010 \text { to } 0.017)\end{array}$ & $\begin{array}{l}0.007 \\
0.004\end{array}$ \\
\hline \multicolumn{4}{|c|}{ 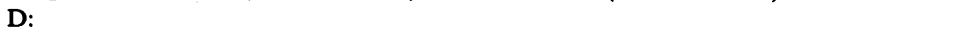 } \\
\hline $\begin{array}{l}\text { left } \\
\text { right }\end{array}$ & $\begin{array}{l}0.070(0.054 \text { to } 0.087) \\
0.056(0.042 \text { to } 0.069)\end{array}$ & $\begin{array}{l}0.035(0.025 \text { to } 0.045) \\
0.027(0.018 \text { to } 0.037)\end{array}$ & $\begin{array}{l}0.001 \\
0.001\end{array}$ \\
\hline $\begin{array}{l}\text { V3I } \\
\text { VI }\end{array}$ & $\begin{array}{l}0.070(0.061 \text { to } 0.079) \\
0.310(0.297 \text { to } 0.323)\end{array}$ & $\begin{array}{l}0.061(0.051 \text { to } 0.069) \\
0.300(0.287 \text { to } 0.313)\end{array}$ & $\begin{array}{l}\text { NS } \\
\text { NS }\end{array}$ \\
\hline
\end{tabular}

differ between patients with presenile and senile Alzheimer's disease.

The linear indices are expressed as means with $95 \%$ confidence intervals in table 2 . They differed significantly between groups, except for left and right B1 and for both indices of general ventricular enlargement. The linear indices of the medial temporal lobe, except left and right $\mathrm{BI}$, correlated significantly with the subjective MTA score $\left(r^{\prime}>0.60 ; p<0.05\right)$.

The mini-mental state examination score correlated significantly with the subjective MTA score, left and right AI, and left DI in Alzheimer's disease patients $(n=21)$. Further neuropsychological testing could be performed in only 19 patients because of severe aphasia in two patients. Correlations of neuropsychological parameters in patients and the subjective MTA score and the linear indices, without BI, are shown in table 3. Because of multiple comparisons (56 correlations) we applied a Bonferroni correction yielding a $\mathrm{p}$ value of $0.05 / 56=0.0009$ - that is, $r^{\prime}>0.70$ (table 3).

The left CI, right CI and right DI did not correlate significantly with any of the neuropsychological parameters. Of the memory tests, object memory after 15 minutes correlated significantly with the subjective score as well as with left AI and left DI.

Discussion

Using subjective visual assessment we found

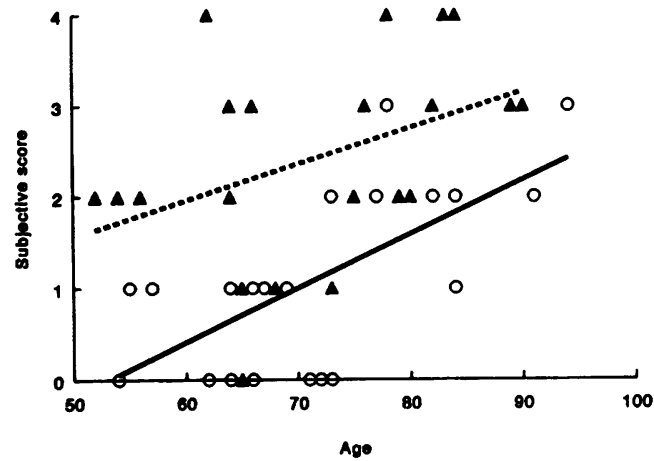

Figure 5 Scatter plot of subjective MTA score versus age in controls (open circles) and Alzheimer's disease patients (closed triangles). Regression lines are drawn in (controls ; Alzheimer's disease - . - - - -).

significant differences in medial temporal lobe atrophy between patients with Alzheimer's disease and age matched controls. This method correctly identified $81 \%$ of Alzheimer's disease patients (sensitivity) and $67 \%$ of controls (specificity). The subjective MTA score correlated well with linear measurements of the medial temporal lobe, which also showed significant differences between groups. Good correlations between visual assessment and linear measurements have been shown earlier in studies of ventricular and sulcal enlargement on $\mathrm{CT}^{15}$ and $\mathrm{MRI}{ }^{20}$

Both types of assessment of MTA did not completely separate Alzheimer's disease patients from controls. The overlap may be explained either by the presence of MTA in a small portion of the controls as an indicator of preclinical Alzheimer's disease or, more likely, by an age related hippocampal atrophy. To elaborate on this further we performed a linear regression analysis with the subjective MTA score as dependent variable. This analysis showed that the subjective score depended significantly on diagnosis (Alzheimer's disease or control) and also on age, and not on sex (see table 4). Post hoc analysis for the two groups separately (fig 5 ) found a correlation with age in the control group $\left(r^{\prime}=0.59, p=0.006\right)$, but not in the Alzheimer's disease group $\left(r^{\prime}=0.37, p=0 \cdot 10\right)$, suggesting a poor sensitivity for the diagnosis of Alzheimer's disease in older patients. From figure 5 it may be inferred that of the seven controls with scores 2 or 3 , six

Table 3 Spearman rank correlations between neuropsychological data and medial temporal lobe atrophy in "probable" Alzheimer's disease patients $(n=19)$

\begin{tabular}{|c|c|c|c|c|c|c|c|}
\hline & \multirow{2}{*}{$\begin{array}{l}\text { Subjective } \\
\text { score }\end{array}$} & \multicolumn{2}{|l|}{$A I$} & \multicolumn{2}{|l|}{$C I$} & \multicolumn{2}{|l|}{$D I$} \\
\hline & & Left & Right & Left & Right & Left & Right \\
\hline \multicolumn{8}{|l|}{ Memory: } \\
\hline Tactile & -0.07 & $0 \cdot 24$ & $0 \cdot 16$ & -0.02 & $-0 \cdot 23$ & -0.32 & $0 \cdot 11$ \\
\hline Sum & -0.29 & 0.35 & 0.44 & $-0 \cdot 17$ & -0.35 & -0.32 & 0.21 \\
\hline Recall after 15 minutes & $-0.79^{\star}$ & $0.71^{\star}$ & 0.49 & -0.30 & $-0 \cdot 15$ & $-0 \cdot 76^{\star}$ & -0.36 \\
\hline Wechsler logical memory & -0.52 & 0.49 & 0.34 & -0.05 & -0.02 & $-0 \cdot 48$ & -0.13 \\
\hline Digit spant & -0.25 & 0.27 & 0.28 & -0.17 & -0.23 & -0.41 & $0 \cdot 17$ \\
\hline \multicolumn{8}{|l|}{ Mental speed: } \\
\hline Trail making test & -0.32 & -0.39 & 0.33 & $-0 \cdot 11$ & $-0 \cdot 28$ & -0.40 & $0 \cdot 21$ \\
\hline Digit symbol substitution test & -0.43 & $0 \cdot 48$ & $0 \cdot 21$ & -0.27 & $-0 \cdot 24$ & -0.47 & -0.04 \\
\hline
\end{tabular}

«Significant correlations after Bonferroni correction $(r>0 \cdot 70)$

TTotal of digits forward and backward. 
Table 4 Multiple linear regression analysis with subjective MTA score as dependent variable

\begin{tabular}{lcccc}
\hline & Value & $S D$ & $t$ & pValue \\
\hline Intercept & 1.184 & & & \\
Independent variable: & 0.046 & 0.40 & 3.43 & 0.0015 \\
$\quad$ Age (years) & -0.36 & -0.14 & 0.999 & 0.32 \\
Sex (male =1) & -1.44 & -0.58 & 4.13 & 0.0002 \\
Diagnosis (Alzheimer's disease = 1) & & &
\end{tabular}

were aged over 77 . In the CT study of de Leon et al sensitivity dropped greatly after the age of $60 .^{6}$

The MRI studies of Seab et $a l^{7}$ and Kesslak et al $^{10}$ found no overlap. This may be explained by several factors that differed from out study. Both studied small groups, consisting of 10 patients and seven controls in Seab et al's study, and eight patients and seven controls in that of Kesslak et al. In such small groups an overlap is less likely to occur. In addition, the mean age of the controls was lower than that of the Alzheimer's disease patients and the oldest patient was 78 years in the former study and 80 years in the latter. Our study not only included more patients but the age range was also wider. The two previous studies used volumetric measures involving only the hippocampus ${ }^{7}$ or both the hippocampus and parahippocampal gyrus. ${ }^{10}$ Although this may be a better way to characterise the medial temporal lobe, it is unlikely that it completely separates age matched controls from Alzheimer's disease patients in larger groups.

Only one patient exhibited a subjective score of 0 . This was a left handed woman of 61 years with a mini-mental state examination score of 16. She suffered from mild aphasia together with astereognosis of the left hand and visuospatial disturbances. She performed reasonably well on the Wechsler logical memory and object memory evaluation tests, illustrating the relatively preserved memory function. One year later her memory functions had worsened. This patient resembles an earlier reported (presenile) Alzheimer's disease patient who presented with focal symptoms instead of definite memory disturbances. ${ }^{21}$

Differences in subjective scores might be due to the preponderance of women in the Alzheimer's disease group, since brain size may be smaller in women. ${ }^{22}$ Although this could have influenced the ranking procedure we think that it is not of major importance since brain width did not differ significantly between groups. Furthermore, within the controls no differences in brain width or subjective score were found between men and women, as in previous reports, ${ }^{9}$ and multiple linear regression analysis did not identify sex as an explanatory variable of the subjective score.

In contrast to earlier reports, ${ }^{15}$ linear indices of the lateral ventricles and third ventricle as indicators of generalised brain atrophy showed no significant differences between the two groups in this study. These indices are well known to correlate with severity of dementia and are of more value in longitudinal studies than in cross sectional studies. ${ }^{23}$ The failure to find significant differences between groups in our study is probably due to small sample size. It does illustrate, however, that in spite of the few subjects MTA differed significantly between groups, and does not (only) reflect overall brain atrophy in Alzheimer's disease. MTA seems to occur early in the disease process $^{24}$ and might be a selective marker for Alzheimer's disease.

The strong correlations of the delayed recall in the object memory evaluation test with some of the MTA variables is striking. Some of the MTA variables also correlated significantly with the mini-mental state examination score. This does not imply, in our opinion, that the correlations with this memory test are just the result of global dementia, since significant correlations with mental speed tests would then also be present. Our findings strongly support the hippocampal model of memory $^{82526}$ and emphasise the potency of MTA for early diagnosis.

From these data we cannot decide which type of assessment of MTA is to be preferred. Linear measurements in general are subject to greater interobserver variability, may vary with the MRI technique, and rely highly on good scan quality (without motion artifacts). Subjective visual assessment seems an easy and quick method. It has been shown to correlate well with computer assisted planimetric and volumetric measurements. $^{20}$

We think that subjective assessment of medical temporal lobe atrophy may be useful to support a clinical diagnosis of "probable" Alzheimer's disease, ${ }^{12}$ enabling the clinician to differentiate this diagnosis from normal aging and "pseudo" dementia-that is, major depression-in subjects younger than 75 years. To date no other types of dementia have been studied with respect to MTA on MRI; therefore the value of assessment of MTA in the differential diagnosis of dementia still has to be established. We thank Drs Gires, Durocher, Vermersch-Langlin, Janssen,
Driessen, and van Oudenaarden, who referred several patients; Violaine Petit and Nathalie Pécheux for neuropsychological assistance; and Mrs E M Van Deventer for expert librarian assistance; and Mrs E M Van Deventer for expert librarian
assistance. This study was supported by grants from Institut National de la Santé et de la Recherche Médicale (INSERM), National de la
CAR 489016.

1 Scoville WB, Milner B. Loss of recent memory after bilateral hippocampal lesions. I Neurol Neurosurg Psychiatry 1957 20:11-21.

2 Zola-Morgan S, Squire LR, Amaral DG. Human amnesia and the medial temporal region. Enduring memory impairment following a bilateral lesion limited to field CA1 of the hippocampus. I Neurosci 1986;6:2950-67.

3 Damasio AR, Eslinger PJ, Damasio H, Van Hoesen GW, Cornell S. Multimodel amnesic syndrome following bilateral temporal and basal forebrain damage. Arch Neurol 1985;42:252-9.

4 Ball MJ, Fisman M, Hachinski V, et al. A new definition of Alzheimer's disease: a hippocampal dementia. Lancet 1985;i:14-6.

5 Tierney MC, Fisher RH, Lewis AJ, et al. The NINCSADRDA work group criteria for the clinical diagnosis of probable Alzheimer's disease: a clinicopathologic study of 57 cases. Neurology 1988;38:359-64.

6 De Leon MJ, George AE, Stylopoulos LA, Smith G, Miller DC. Early marker for Alzheimer's disease: the atrophic hippocampus. Lancet 1989;ii:672-3.

7 Seab JP, Jagust WJ, Wong STS, et al. Quantitative NMR measurements of hippocampal atrophy in Alzheimer's disease. Magn Reson Med 1988;8:200-8.

8 Press GA, Amaral DG, Squire LR. Hippocampal abnormalities in amnesic patients revealed by high-resolution magnetic resonance imaging. Nature 1989;341:54-7.

9 Jack CR Jr, Twomey CK, Zinsmeister AR, Sharbrough FW, Petersen RC, Cascino GD. Anterior temporal lobes and 
hippocampal formations: normative volumetric measurements from MR images in young adults. Radiology 1989; 172:549-54.

10 Kesslak JP, Nalcioglu O, Cotman CW. Quantification of magnetic resonance scans for hippocampal and parahippocampal atrophy in Alzheimer's disease. Neurology 1991;41:51-4.

11 Folstein MF, Folstein SE, McHugh PR. "Mini-mental state". A practical method for grading the cognitive state of patients for the clinician. F Psychiat Res 1975 12:189-98

12 McKhann G, Drachman D, Folstein M, et al. Clinical diagnosis of Alzheimer's disease: report of the NINCDSADRDA work group under the auspices of department of health and human services task force on Alzheimer's disease. Neurology 1984;34:939-44

13 Hachinski VC, Iliff LD, Zilhka E, et al. Cerebral blood flow in dementia. Arch Neurol 1975;32:632-7.

14 Leys D, Soetaert G, Petit H, Fauquette A, Pruvo JP, Steinling M. Periventricular and white matter magnetic resonance imaging hyperintensities do not differ between Alzheimer's disease and normal aging. Arch Neurol 1990;47:524-7.

15 Leys D, Pruvo JP, Petit H, Daudet Y, Clarisse J. Maladie d'Alzheimer. Analyse statistique des résultats du scanner X. Rev Neurol (Paris) 1989;145:134-9.

16 Fuld PA. The Fuld object-memory evaluation. Chicago: Stoelting Instrument Co, 1981 .

17 Wechsler D. Wechsler memory scale revised manual. San
Antonio: Harcourt Brace Jovanovich, 1987

18 Lezak MD. Neuropsychological assessment. New York: Oxford University Press, 1976:266-9.

19 Wechsler D. Wechsler adult intelligence scale restandardized (WAIS). New York: Psychological Corporation, 1955.

20 Wahlund LO, Agartz I, Almqvist O, et al. The brain in healthy aged individuals: MR imaging. Radiology 1990;

21 Crystal HA, Horoupian DS, Katzman R, Jotkowitz S. Biopsy-proved Alzheimer's disease presenting as a right parietal lobe syndrome. Ann Neurol 1982;12:186-8.

22 Gur RC, Mozley PD, Resnick SM, et al. Gender differences in age effect on brain atrophy measured by magnetic resonance imaging. Proc Natl Acad Sci USA 1991; 88:2845-9.

23 De Leon MJ, George AE, Reisberg B, et al. Alzheimer's disease: longitudial $C T$ studies of ventricular change. AfNR 1989;10:371-6.

24 George AE, De Leon MJ, Stylopoulos LA, et al. CT diagnostic features of Alzheimer's disease: importance of the choroidal/hippocampal fissure complex. AfNR 1990;11:101-7.

25 Hyman BT, Van Hoesen GW, Damasio AR. Memory related neural systems in Alzheimer's disease: an anatomic study. Neurology 1990;40:1721-30.

26 Sass KJ, Spencer DD, Kim JH, Westerveld M, Novelly RA, Lencz T. Verbal memory impairment correlates with hippocampal pyramidal cell density. Neurology 1990; 40:1694-7. 